\title{
A REQUIREMENT MODEL FOR LEAN LEADERSHIP IN CONSTRUCTION PROJECTS
}

\author{
Rory Walter ${ }^{1}$, Marc Weinmann², Carolin Baier ${ }^{3}$, \\ Svenja Oprach ${ }^{4}$, and Shervin Haghsheno ${ }^{5}$
}

\begin{abstract}
A growing number of construction companies are implementing the Lean philosophy to improve the customer's value and identify waste. A recently conducted survey with corporate members of the LCI showed that main barriers in Lean implementation are managerial based. Many construction companies mainly focus on the implementation of Lean Construction methods and tools and often social factors for cultural change are neglected. To achieve the required change, site managers play a very important role as the linkage between the people responsible for value-adding activities on the construction site and the top management. A role shift is necessary, which results in changing requirements for leadership: From a strongly centred role of a manager to the role of a leader. The new leadership role has both to support collaboration between subcontractors and to continuously improve the skills and knowledge of the individuals.

Based on a comprehensive literature study in the field of Lean Leadership and leadership approaches in general, the authors develop a requirement model for construction managers for the Lean transformation process. The requirement model can serve as a basis for further research and the development of further training programs for construction managers.
\end{abstract}

\section{KEYWORDS}

Lean Construction, Lean Leadership, culture change, requirements

\section{INTRODUCTION}

There is a growing realization of the importance of leadership in Lean, but the meaning of Lean and leadership differs from author and research field. Orr (2005, p. 346) noted that it is often easier to agree what Lean and leadership are not, than to agree on a comprehensive definition. This paper focus on Lean Leaderships on construction site.

1 MSc Student, Karlsruhe Institute of Technology, 76131 Karlsruhe, Germany, +49-721-608-42647, rwalter@,vollack.de, orcid.org/0000-0002-8405-1029

2 BSc Student, Karlsruhe Institute of Technology, 76131 Karlsruhe, Germany, +49-721-608-42647, marc.weinmann@student.kit.edu, orcid.org/0000-0003-3871-0553

3 Research Fellow, Karlsruhe Institute of Technology, 76131 Karlsruhe, Germany, +49-721-608-48265, carolin.baier@kit.edu, orcid.org/0000-0002-2790-9586

4 Research Fellow, Karlsruhe Institute of Technology, 76131 Karlsruhe, Germany, +49-721-608-48265, svenja.oprach@,kit.edu, orcid.org/0000-0002-0376-1791

5 Professor, Karlsruhe Institute of Technology, 76131 Karlsruhe, Germany, +49-721-608-42646, shervin.haghsheno@kit.edu, orcid.org/0000-0002-0602-6370 
Especially which leaderships skills are required for a site manager for successfully leading the project.

Liker $(2014$, p. 30) describes the Lean principles according to the 4P model of the Toyota Way with "problem solving", "process", "philosophy", and also "people and partner". However, companies usually focus on the processes and the elimination of waste within these processes. The consideration of the "people" is often left out. Often longterm thinking is missing, and an appropriate development of managers is neglected. In order to achieve a successful Lean Transformation, the human factor and leadership must also be taken into consideration. Also, a conducted survey with LCI members in 2018 pointed out big barriers in Lean implementation on a management level. Here, as a result within the top three highest ranked barriers were named: A lack of top management support (1), a misperception about Lean practices (2) and lack of information sharing and integrated change control (3) (Demirkesen et al. 2019, p. 165).

Following a site manager plays a highly important role for taking over these responsibilities. As the linkage between the people responsible for value-adding activities on construction site and the top management. The site manager must convince top management about the benefits in applying Lean, communicate in a common Lean structure and share important information to coordinate all people involved. By implementing Lean within construction companies, a role shift takes place: From a strongly centred role of a manager to the role of a leader. The changing requirements towards successful Lean Leadership result in a new important focus both in research and in practice.

Lean Leadership is an essential component for a sustainable cultural change (Orr 2005, p. 345) and includes the integration of Lean principles into leadership behavior. Lean Leadership differs from leadership in conventional forms of organization in its teamoriented approach. By changing from a problem orientation to a solution orientation, all team members should be geared towards identifying and solving problems together, sustainably, and directly (Marquardt 2018, p. 465). Further on, studies showed that leadership has an important influence on the work efficiency (Braun et al. 2013).

To create and support an efficient way of working and to support the cultural change on construction sites, requirements for Lean Leadership have to be defined. So far in research and practice the focus is predominantly in the application of methods and tools (Dombrowski and Mielke 2014; Mann 2009; Orr 2005). Mossman (2015) lists needed knowledge about methods and tools as well as several skills a Lean Leader should have. These are applied in Lean Leadership trainings and benefits are checked by Hackler (2018). To distinguish needed knowledge of methods and tools to skills focus of this paper is to create a simplified categorization system showing an overview of Lean Leadership skills. This paper has the objective to unveil necessary requirements to support Lean Leadership in construction projects by a comprehensive literature review and an adaption of the existing leadership model to construction. The resulting requirements model serves as a basis for further studies.

\section{RESEARCH METHOD}

Through a literature study on Lean Leadership, the relevant publications were first identified by means of a keyword search. First, we conducted a literature study with the keywords "Lean Leadership" and "Construction". It is notable, that the necessary cultural change in the management of a construction project is treated very imprecisely. Although a large number of publications in the field of cross-industry leadership research and Lean 
Leadership is existing, current publications in the construction sector are limited. Orr (2005) also unveils the need for research in Lean Leadership in construction and describes nine Lean Leadership behaviors for contractors but without particularly focus on site managers.

Keiser (2012) further concentrates on essential conditions as basis for Lean Leadership. The personal requirements of the leader are not focus of this publication. The lack of adaptation of the requirements for a Lean Leader to the construction sector can be interpreted as the assumption that this is a special type of leadership.

To identify and define requirements for a Lean Leader in construction the keywords were changed to "Lean Management" and "leadership" and "requirements". Here, essential contributions were made by Liker (2014), Claushues and Hurtz (2018), Dombrowski and Mielke (2013), Mann (2009), Orr (2005), Spear (1999) and the Verein Deutscher Ingenieure (VDI 2019). These authors use the predefined keywords in combination as basis of their work and thus analysis the requirements of a Lean Leader. A backward search within the identified literature was used to gradually collect further sources as basis for the development of the requirements model. Here a relation to Lean Construction and the origin of Lean Leadership at Toyota is highlighted. A forward search was used to collect the essential data of leadership research. Starting from the early leadership research, further developments are investigated. Out of the full list of the identified literature requirement, criteria were categorized and then structured in a model.

To get a full requirement criteria list for construction, there are three main elements from the literature research which were compared: Lean Leadership at Toyota, the traditional leadership understanding in construction and existing Lean Leadership definitions in construction. By comparing all, missing elements can be identified and summarized in a requirements model. Within the requirements model, the relevant requirements from a century of leadership research are brought in line with the requirements from recent research on Lean Leadership for construction industry. Therefore, in the following chapters we first define Lean Leadership at Toyota in the origin, then in traditional leadership style and last existing definitions for Lean Leadership in construction. The resulting requirements model is the result.

\section{COMPARISON OF EXISTING LEADERSHIP MODELS}

\section{LEAN LEADERSHIP MODEL AT TOYOTA}

According to Liker and Convis (2012, p. 7), a restructuring of the DNA of a company starts with people, but above all with management. In order to facilitate the transition to cross-industry Lean Leadership, first Toyota's understanding of leadership according to Liker is described (2014, p. 260). In his paper "The Toyota Way", the 9th of 14 principles states that managers must be developed to know and understand all work processes. In doing so, they must exemplify the corporate philosophy and communicate it to other stakeholders. Toyota has not developed by recruiting leaders, but by creating them within its own company (Shang 2014, p. 1146). In "the Toyota way to Lean Leadership", Liker and Convis (2014, p. 247) describe the development of all employees within the organization, and the conviction that the employee is the most valuable resource, as Toyota's recipe for success.

Toyota's leadership model therefore distinguishes between two approaches: The bottom-up approach and the top-down-approach. In the bottom-up approach employees are involved in decision-making processes. The role of the manager is to develop and 
motivate the employee. In addition, the top-down approach can also be pursued under special conditions. Here, employees are guided by instructions from higher hierarchical levels. A further distinction can be made between generalists with a broad range of skills and specialists with profound and detailed expertise. A more detailed subdivision distinguishes four types of managers (Liker 2014, p. 260):

The bureaucratic managers have only general management skills, thanks to which they introduce rules and measuring instruments from their superior position in order to comply with regulations.

The group facilitators have no technical understanding of the work processes, but still try to develop their staff. By means of moderation and support skills, they can encourage employees to strive for the common goal.

The commanders have a profound knowledge. However, their social skills are limited to a minimum. They lead in an authoritative and ordering manner without involving the employees in decision-making processes.

The creators of a learning organization have both social skills and the necessary technical understanding of work processes. Leadership is based on questions that lead employees to make independent decisions and actions.

Liker $(2014$, p. 261) notes that a Toyota manager must be able to combine all four characteristics, depending on the situation. However, the approaches are critically questioned. Can bureaucratic managers use metrics to achieve customer satisfaction and create a learning organization? Can group facilitators develop their employees without a profound understanding of the work processes? Can commanding officers manage each activity independently without losing control? (Liker 2014, p. 261)

The core of Lean Leadership at Toyota is to create a learning organization through a profound knowledge in work processes and a bottom-up approach.

\section{TRADITIONAL LEADERSHIP IN CONSTRUCTION}

In the organizational structure of a traditional construction project, the site managers are located at the position between the operations level and the top management level. In terms of hierarchy they are inferior to the company management and the project management. They use the top-down approach by handing over the targets of the top management and project management to the operations level. In general, each trade is carried out by a different company and is contractually bound to the owner or a general contractor. The high degree of fragmentation and the hierarchical structure result in deficits in coordination and communication between the parties involved. The definition of objectives as well as instructions and rules are traditionally delegated from the site management level to the operational level without involving the expertise of the operational units. The role of the "commander" is therefore the most frequently exercised role of a site manager by the given system of traditional construction projects. As a result, incomplete or incorrect information is often passed on at the end of the communication chain (Kirsch 2009, p. 54).

The Lean Transformation process turns the traditional organizational structure upside down. Kirsch $(2009$, p. 54) describes the "bottom-up" perspective as a paradigm shift that is necessary for the implementation of a Lean production system in the construction industry. This restructuring leads to a changed task profile for middle management, which includes project and construction management of the main contractor. To support a full cultural change, the current "commanding" role in construction has to be completed with missing management styles towards the bottom-up approach. 


\section{LEAN LEADERSHIP IN CONSTRUCTION}

Existing definitions for construction show that Lean Leadership in construction is more than the ability of playing all management roles:

According to VDI 2553 of the "Verein Deutscher Ingenieure" (2019, p. 34), the promotion of cooperative behavior and teamwork is the focus of Lean Leadership in construction. The manager, whether working in construction realization or design, is considered as an expert in their processes, giving him the role of "problem solver" and "process improver". Lean Leaders must be aware that they are not the person who add value to the product. The guided workers on the construction site create the value for the customer. Leadership can only provide the necessary conditions for optimal value creation (Dombrowski and Mielke 2013, p. 570). Dombrowski and Mielke (2013, p. 570) describe Lean Leadership as a methodical system for the sustainable implementation and continuous improvement of a Lean Production System. It describes the collaboration between managers and employees in their common pursuit of perfection. The customer orientation of all processes as well as the development of employees and managers are a main element. Managers should be enabled to develop their employees in a way that they are not only able to solve their own problems independently. Rather, they should also continuously improve processes throughout the entire organization.

Lean Leadership in construction is therefore the missing link between culture, system, and organization. Here, culture describes the corporate values and the personal motivation, attitude of construction workers and the top management. The system describes the visible elements. These include the value creation processes and construction infrastructure, as well as the Lean principles and methods applied. The organization includes the company's organizational structure, the skills and involvement of workers, and the handling of knowledge and information (Dombrowski 2016, p. 6). A Lean Leader in construction must therefore provide the necessary conditions for optimal value creation (Dombrowski and Mielke 2013, p. 570), creating an environment in which a team can establish itself and pursue a common goal (Fiedler 2012, p. 33).

Fiedler (2012, p. 33) also sees Lean Leadership as the critical factor by which the success or failure of Lean initiatives can be measured. The manager's task should be to create a working environment in which a team can establish itself. This team must pursue common goals by acting together. In addition, a learning culture must be conveyed that promotes change in the pursuit of these goals.

Creating a learning culture in a project organization exposes the main structure for a full requirement leadership model in construction. In comparison to the general leadership models of Toyota, also the special project character of construction must be considered and centred in the structure of the model. In construction, organization are in an on-going change by the project-based nature of business. Improvements must be transferred and continuously updated as well as adapted to the current situation. The situational analysis and matching management style therefore need to be the fundamental structure of the requirements model for construction. With the cultural change in construction selecting and training the right skills of leaders will become in the future more crucial.

\section{REQUIREMENT MODEL}

Based on the literature study, requirements for a site manager resulting from a Lean Leadership perspective were identified and summarized in a requirement model. The model represents the basic requirements for a site manager regarding personality, abilities, 
and tasks as Lean Leader on the construction site. As a problem solver, process improver and enabler in the Lean transformation process, he must not only develop and empower the operational staff, but also continuously develop, reflect, and improve himself. In addition, as the linkage between the people responsible for value-adding activities on construction site and the top management, the site manager is confronted with direct requirements such as self-development or qualification of employees and subcontractors as well as indirect requirements from top management like the establishment of a uniform corporate culture and changed organizational structures, which must be fulfilled by him in order to increase value creation in the entire company.

The Lean Leadership requirements as result of the literature study can be divided into four categories: Basic requirements, leadership situation, style and responsibilities (Error! Reference source not found.). It provides the basis for the development of a selection, qualification, and development process of site managers.

\section{Basic requirements}

The basic requirements are the foundation for successful leadership in construction projects and sustainable implementation of the Lean philosophy. These are not only the characteristics of the leader, but also the organizational structure, the improvement culture and Hoshin Kanri. If the basic requirements are fulfilled, further training as described for example by Hackler et al. (2017) and development concepts for construction managers can be developed on this basis.

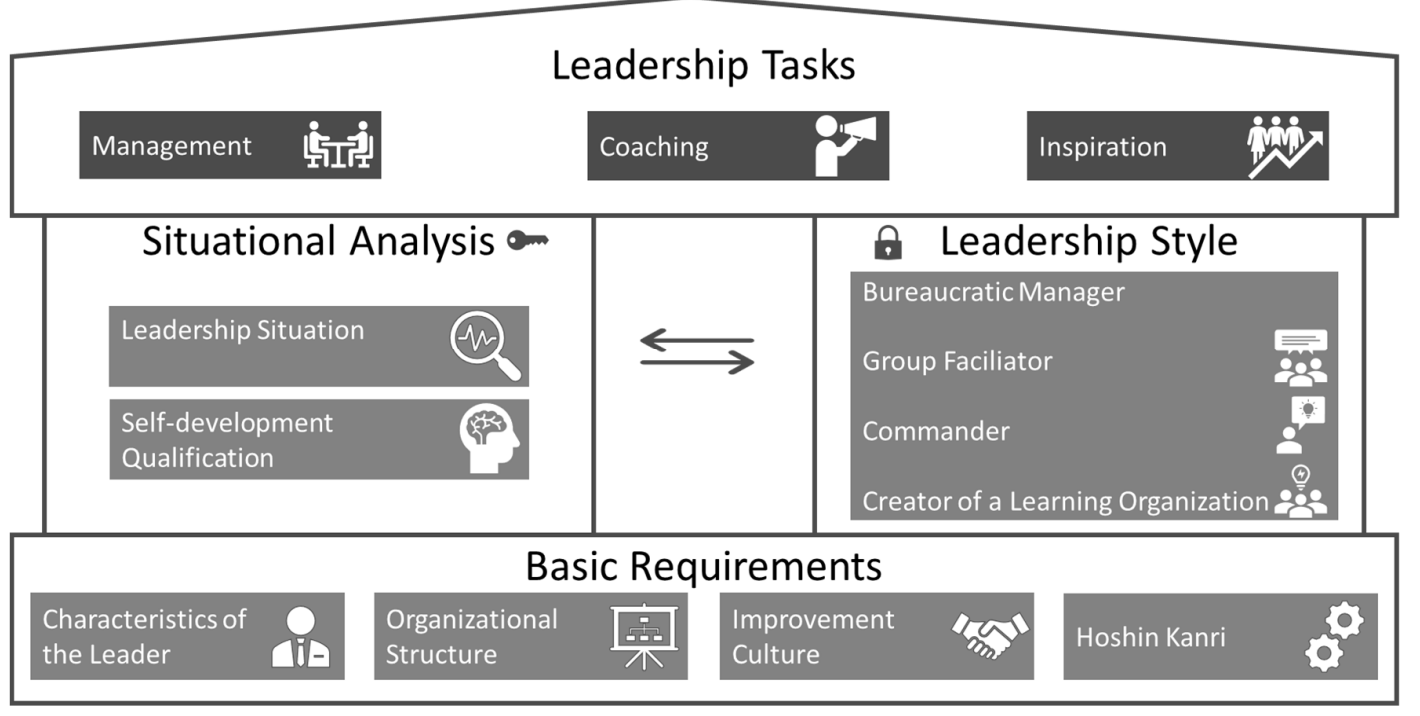

Figure 1: Requirement model for Lean Leaders in Construction

The cultural change in leadership requires a selection of suitable site managers according to their characteristics. Instead of a "commander" with an authoritarian and ordering leadership style a collaborative "creator of a learning organization" at eye level is needed.

Beside of the characteristics of the leader an improvement culture must be implemented. The site manager as leader of the constructions site is responsible to create an environment so that workers feel psychological safe on site. While currently penalties are often imposed in response to mistakes and problems, in the future it will be necessary to create a culture of open asking questions, asking for help, or speaking up when errors occur. Therefore it is important to see errors as opportunities of learning not to fear, focus 
on learning from others and building a platform to occur innovations and increase familiarity among project participants (Gomez et al. 2019, p. 1043; Dombrowski and Mielke 2014, p. 567). The requirement for the site manager is therefore to act as a role model.

The subcontractor must be integrated into a continuous improvement process by encouraging the subcontractor to question its own processes and enabling him to solve problems independently (Verein Deutscher Ingenieure 2017, p. 7).

Another basic requirement to create a learning organization is the organizational and project structure. The construction site as a place of value-adding activities demands a well-considered structure and organization of a company. On the one hand, the site manager needs the support of top management in the implementation of Lean methods. On the other hand, it must be ensured that the operative, value-adding personnel are involved in decisions and the design of processes. The traditional top-down structure does not achieve appropriate communication. Skilled workers who carry out value-adding activities typically do not take part in planning meetings and receive the information necessary for execution via detours. This information may reach the skilled worker with gaps or errors. (Kirsch 2009, p. 54) The requirement for construction management is to involve the skilled worker or foreman in decision-making processes. Meetings must take place in regular cycles at the place of value creation in order to achieve and maintain complete communication.

The third requirement for site management is the coordination of objectives, the Hoshin Kanri (in English: "Management by Policy") principle. Increasing customer value as the primary goal in Lean implementation requires a clear definition of project objectives, especially in construction projects. Experience in the past has shown that in many constructions projects customer value is often not integrated into project execution or is integrated at a late stage. At the same time, overarching corporate goals must be defined for the construction company. These Goals must be addressed in each project hierarchy together with the owner and translated into a need for action, personal tasks and for the subcontractor (Dombrowski und Mielke 2014, p. 569).

\section{Situational analysis and leadership style}

The application of Lean principles on construction sites has resulted in various new situations that counteract the classic "commander" leadership style. In weekly or even daily meetings, all project participants on the construction site are involved in decisions, and within the Takt Planning and Takt Control (TPTC) methodology or the Last Planner System (LPS) direct communication between the contractors is facilitated. Furthermore, the aim is to break down the corporate values from top management to each individual employee.

The Lean principles of continuous improvement result in requirements for the selfdevelopment and qualification of employees, which are based on an assessment of the situation. Without an assessment of the abilities of the manager and the individual employees, goal-oriented development is not possible. Self-development is not only aimed at the further development of one's own abilities. The manager thus acts as a role model whom the employees follow. Self-reflection should also shed light on leadership behavior. According to Dombrowski and Mielke (2014, pp. 568-569), managers must reflect on their own management style and learn a cooperative style to encourage employees to question their own actions too. If the manager can openly admit their own 
mistakes, the foundation is laid for a "no blame" culture in which admitting mistakes and difficulties solves problems at an early stage.

Education and training programs for construction managers should be designed to enable them to develop these skills.

The situation analysis in Lean Leadership not only includes the analysis of the situation itself, but also the independent questioning of the site manager's own abilities and performance.

Leadership research shows that the leadership style should always be adapted to the respective leadership situation, especially due to the fact of cooperation of different characters in a construction project in combination with changing external boundary conditions. The challenge here lies in the right choice of leadership style. The literature on Lean Leadership varies in terms of leadership style. Dombrowski and Mielke (2014, pp. 568-569) recommend a more cooperative behavior in general compared to an authoritarian "commander" leadership style. This paper pursues the assumption of Claushues and Hurtz $(2018$, p. 129) that a leadership behavior adapted to the situation is necessary. Leadership behavior must therefore be adapted to the motivation and ability of the employee. If the employee is demotivated and not capable, they must be led with a "telling" style through precise instructions. Contrary to this, it is necessary to lead the motivated and empowered employee. Here the responsibility and execution are left to the employee. The managers as "creators of a learning organization" only intervenes in the decision-making and occasional checks. They adopt a delegating management style. Accordingly, the management situation must be examined in more detail in order to develop optimal management behavior (Claushues and Hurtz 2018, p. 129).

Different situations require different leadership styles. Therefore, a flexible choice of leadership style is needed. The choice of the right style is based on the continuous analysis of the situation. If the consideration of dependence between the choice of leadership style and the current situation is neglected, symbolically the leadership building collapses.

\section{Leadership tasks}

In Lean Leadership, the leadership tasks of a construction manager can be classified in "management", "coaching" and "inspiration". These tasks build on the existing principles and supplement the basic prerequisite and behavior with a specific approach. While "management" tasks do not particularly differ from the previous range of tasks in construction management, "coaching" and "inspiration" represent a new requirement for site managers. Projects in which Lean Leadership is practiced need managers who can radiate enthusiasm and who can motivate and convince employees and subcontractors. (Claushues and Hurtz 2018, p. 18) Like transformational leadership, morale and motivation should be increased. Coaching is used to demonstrate the social competencies of the manager. The manager must convey appreciation and communicate at eye level to achieve respect and acceptance.

The third task of a manager is to inspire and motivate employees. Employees cannot be forced into motivated work. In order to achieve top performance, the sense of the work must be recognized. This is made easier in an inspiring work environment. The challenge for site management is therefore to create this prerequisite through inspiring leadership. An inspiring leader must convey the meaning and goal of his or her task to the employee. By questioning the fundamental purpose of the activity or work, the employee should independently develop an understanding of the importance of their work. (Claushues and Hurtz 2018, p. 18) 
The resulting requirement model has four main elements: In order to perform the management tasks, there needs to be set basic requirements. To deal with the project character and set a continuous improvement process from construction to construction, the situational analysis becomes crucial. Here, based on the situational analysis a leadership style has to be selected. The resulting model is a first visualized summary of requirements for Lean Leadership in construction, which needed to be empirically validated. The derived model is a first summary of requirement especially for site managers.

\section{CONCLUSION}

Lean Construction represents a significant opportunity for the development of the construction industry. The implementation of methods and tools developed based on Lean Management principles already show the potential for change in practice. The failure of such change often finds its cause in the failure of cultural change. While methods and tools are accepted the way of thinking of employees, managers and project partners must also undergo this change. In order to achieve a given goal, the managers must always reflect on their own behavior and adapt it to the situation. Managers on the construction site must consider the starting position of the subcontractor, the working climate within the project team and the quality of task structuring.

Furthermore, it is the manager's task to create the optimal conditions for the valueadding activities. This includes the continuous development of own skills and knowledge as well as the promotion of the employees and subcontractors within the project. In addition, site management must strive for a culture of improvement within the project team, in which the common pursuit of perfection is a primary goal. The problem orientation must give way to a solution orientation, in which errors are regarded as an opportunity for improvement. Problem solving should be based on researching the cause rather than searching for the culprit. In addition, communication and interaction must take place at the place of value creation. In cooperation with the experts at the place of value creation, problems should be discussed and lastingly solved. This includes the involvement of the subcontractor in decision-making processes. In addition, the site manager must explore the company and project goals and coordinate those with the project participants. The project participants must be assigned their tasks for the joint achievement of objectives.

In the context of the development of the subcontractors it is the task to coach and inspire them. By communicating the fundamental purpose of all activities, an increased motivation in the entire project team is achieved. The qualification through coaching leads to an independent analysis of the processes by the subcontractor itself. Optimization potentials and problems are recognized and independently tackled by them.

More and more companies are making it their business to establish Lean Management approaches within their organizations. The development of employees to establish a Lean culture will need to be more focused in the future. It is the people who are responsible for successful change, not the methods and tools. The developed requirements model (figure I) offers a basis towards the long-term development of managers. Based on this model, development programs can be designed which convey the requirements and the need for action to the managers. Care should be taken to ensure that the development builds on the existing programs. An example of a Lean Leadership training shows Hackler et al. (2018) for a full construction organization. Here, the results of a survey show that Lean Leadership trainings show big benefits, also on a change of personal behavior. 
Situational circumstances, appropriate leadership behavior, and principles of Lean Leadership must be further empirically investigated to further prove personal and measurable benefits out of Lean Leadership. First studies in leadership show an improvement in work efficiency (Braun et al. 2013).

\section{REFERENCES}

Braun, S., Peus, C., Weisweiler, S. and Frey, D. (2013). "Transformational leadership, job satisfaction, and team performance: A multilevel mediation model of trust." The leadership Quartely, 24 (2013), 270-283, Munich, Germany.

Claushues, J. and Hurtz, A. (2018). "Lean Leadership: Agiles Lean gelingt nur mit den Menschen [Lean Leadership: Agile Lean can only succeed with people]." BusinessVillage, Goettingen, Germany.

Demirkesen, S., Wachter, N., Oprach, S., and Haghsheno, S. (2019). "Identifying Barriers in Lean Implementation in the Construction Industry." Proc. $27^{\text {th }}$ Annual Conference of the International Group for Lean Construction (IGLC 27), Dublin, Ireland, 157168.

Dombrowski, U. and Mielke, T. (2014). "Lean Leadership - 15 Rules for a Sustainable Lean Implementation.” Procedia CIRP (17), Braunschweig, Germany, 565-570.

Fiedler, M. (ed.) (2018) "Lean Construction - das Managementhandbuch: Agile Methoden und Lean Management im Bauwesen [Lean Construction - the management handbook: Agile methods and lean management in construction]." Springer Gabler, Berlin, Germany.

Gomez, S., Bishop, B., Ballard, G., Saenz, M., and Tommelein, I.D. (2019). "An Active Caring Approach Through Psychological Safety in Construction Projects." Proc. $27^{\text {th }}$ Annual Conference of the International Group for Lean Construction (IGLC 27), Dublin, Ireland, 1037-1048.

Hackler, C., Byse, E., Alves, T.C.L., and Reed, D. (2018). "Lean Leadership Training: Lessons from a Learner-Centered Analysis." Proc. 26th Annual Conference of the International Group for Lean Construction (IGLC 26), Chennai, India, 484-494.

Hackler, C., Byse, E., Alves, T.C.L., and Reed, D. (2017). "Building a Lean Culture." 25th Annual Conference of the International Group for Lean Construction (IGLC 25), Heraklion, Greece, 309-316.

Hurtz, A. and Stolz, M. (2016). "Shop-Floor-Management: Wirksam führen vor Ort [Shop-Floor-Management: effective leadership on site].", BusinessVillage, Goettingen, Germany.

Keiser, J.A. (2012). "Leadership and Cultural Change: Necessary Components of a Lean Transformation." Proc. 20th Annual Conference of the International Group for Lean Construction (IGLC 20), San Diego, USA.

Kirsch, J. (2009). "Organisation der Bauproduktion nach dem Vorbild industrieller Produktionssyteme: Entwicklung eines Gestaltungsmodells eines Ganzheitlichen Produktionssystems für den Bauunternehmer [Organization of construction production on the model of industrial production systems: development of a design model of an integrated production system for the contractor.]." Universitätsverlag Karlsruhe, Karlsruhe, Germany.

Liker, J.K. (2014). "Der Toyota-Weg: 14 Managementprinzipien des weltweit erfolgreichsten Automobilkonzerns [The Toyota Way: 14 management principles of the world's most successful automotive group]." FinanzBuch-Verl., Munich, Germany. 
Liker, J.K. and Convis, G.L. (2012). "The Toyota way to Lean Leadership: Achieving and sustaining excellence through leadership development." McGraw-Hill Professional, Maidenhead, England.

Mann, D. (2009). "The Missing Link: Lean Leadership." Frontiers of Health Services Management, 26(1), 15-26.

Marquardt, C. (2018). "Lean Leadership- Beitrag in Lean Construction - das Managementhandbuch: Agile Methoden und Lean Management im Bauwesen [the Management Handbook: Agile Methods and Lean Management in Construction]." Springer Gabler, Berlin, Germany, 465-485.

Mossman, A. (2015). "Bringing lean construction to life: Developing leaders, consultants, coaches, facilitators, trainers \& instructors." Proc. 23rd Annual Conference of the International Group for Lean Construction (IGLC 23), Perth, Australia, 413-423.

Orr, C. (2005). "Lean Leadership in Construction." Proc. 13th Conference of the International Group for Lean Construction (IGLC 13), Sydney, Australia.

Shang, G. (2014). "Toyota Way Lean Leadership: Some Preliminary Findings from the Chinese Construction Industry." Proc. 22nd Annual Conference of the International Group for Lean Construction (IGLC 22), Oslo, Norway, 1145-1156.

Spear, S.J. (1999). "Decoding the DNA of the Toyota Production System." Harvard Business Review, Boston, USA, 96-106.

Verein Deutscher Ingenieure (2017). "VDI 2871 - Ganzheitliche Produktionssysteme Führung [VDI 2871 - Comprehensive production systems Leadership]." VDI 2871, Berlin, Germany. 
A Requirement Model for Lean Leadership in Construction Projects

This page was intentionally left blank. 